\title{
Data-Based Value Co-Creation in Smart Service Systems: A Reinterpretation of Customer Journey
}

\author{
Mara Grimaldi ${ }^{1}$, Maria Vincenza Ciasullo ${ }^{1}$, Orlando Troisi ${ }^{1} \&$ Paola Castellani $^{2}$ \\ ${ }^{1}$ Department of Business Science, Management \& Innovation Systems (DISA-MIS), University of Salerno, \\ Fisciano, Salerno, Italy \\ ${ }^{2}$ Department of Business Administration, University of Verona, Verona, Italy \\ Correspondence: Mara Grimaldi, $\mathrm{PhD}$ in Marketing and Communication, Department of Business Science, \\ Management \& Innovation Systems (DISA-MIS), University of Salerno, Via Giovanni Paolo II, 132, Fisciano \\ (SA), 84084, Italy. E-mail: margrimaldi@unisa.it
}

Received: November 6, 2019

Accepted: March 5, 2020

Online Published: May 30, 2020

doi:10.5539/ijbm.v15n6p212

URL: https://doi.org/10.5539/ijbm.v15n6p212

\begin{abstract}
Industry 4.0 is characterized by the key role of new technologies in the development of relationships between companies and their stakeholders. Thus, the most recent theories on service redefine organizations as complex service systems that create and co-create value thanks to the interactions between actors, enhanced by smart technologies and ICTs.

In particular, the concept of service systems- introduced in Service Science- seems to be suitable for the exploration of how service design, and the processes of innovation sharing and emergence, can be strengthened thanks to the application of smart technologies.

Despite the adoption of a system logic, service systems, and their conceptualization, need to be reinterpreted according to a perspective that applies a total and all-encompassing view to the processes of value generation and to the interpretation of the information and data exchanged (data-driven decision-making).

Therefore, the study proposes a conceptual model that integrates the key enabling factors of value co-creation in service systems with the main strategic drivers introduced in data-driven approach to redefine the entire service experience as a service journey. In this continuous information flow, providers, customers and users share and combine data streams, to be turned into relevant information and value, through an integrated and interacting set of touch points that connect the different stages of service creation, delivery and co-creation.
\end{abstract}

Keywords: smart service systems, big data, data-driven decision-making, value co-creation, customer journey

\section{Introduction}

In today's interconnected world, the huge amount of data available to companies, at an increasingly rapid pace, unimaginable until a few years ago, reshapes inevitably the social and economic configuration of markets, by determining the transition to the so-called industry 4.0 (Kagermann, Lukas, \& Wahlster, 2011). The opportunities offered by multi-channel strategies (Rangaswamy \& Van Bruggen, 2005; Neslin et al., 2006), a key feature of 4.0 Marketing (Cao \& Li, 2015), increase the possibilities for companies to interact with customers and partners, by making communication and information/data exchange potentially continuous. However, if on the one hand the multiplication of the points of contact and interaction between organizations and their stakeholders, the so-called touchpoints, seems to offer an immeasurable benefit, on the other hand there is still the need to shed light on the way in which data flows can be optimized. In this way, the potentiality of smart technologies and ICTs (information and communication technologies) can be exploited fully by preventing the risk of transforming technological opportunities into threats (Gandomi \& Haider, 2015).

Therefore, companies need to adopt an orientation aimed at exploring and seizing consumers' motivations, attitudes and behaviours across the multiple technological channels available for stakeholders' relationships management. There is, thus, the urgent need to understand how the new technologies (from ICTs to marketing analytics and engagement platforms) can redefine decision-making process both of the organizations (Neslin et al., 2006) and of consumers, which, at any time, can exchange, co-create and reframe their opinions mutually. 
In the light of the impact of Big Data on the efficiency of business decisions, a new research stream has been proposed in knowledge and information management: the data-driven decision-making (DDDM, LaValle, Lesser, Shockley, Hopkins, \& Kruschwitz, 2011; Brynjolfsson, Hitt, \& H. Kim, 2011). Based on the adoption of an all-embracing data-mind-set, this approach can enable a better understanding of how the use of contemporary technological tools can increase the efficiency of business decision-making (Erevelles, Fukawa, \& Swayne, 2016; Ortiz-Repiso et al., 2018).

Therefore, the study aims at reinterpreting contemporary complex organizations as smart service systems according to a data-driven perspective that can permit to explore: 1) how ICTs can act as enablers of value and potential innovation; 2) how to optimize and manage strategically data, information and value through the multiple technological channels connecting users and providers.

In fact, the existing technology platforms and analytics provide both companies and customers/users with interconnected touchpoints that facilitate and intensify their processes of choice reciprocally. At the same time, the moments of interactions users-providers (service encounter) are multiplied, by virtualizing experiences (service experience) and broadening increasingly customer journey (Lemon \& Verhoef, 2016; Voorhees et al., 2017) to create a totalizing service journey.

Despite the recognized need, formalized in literature, to analyse the role of technology as a driver for value co-creation, until now the identification of the key strategic factors for an efficient and responsible use of smart technologies has not yet been advanced (Breidbach \& Maglio, 2016; Lim \& Maglio, 2019).

Therefore, the work introduces a conceptual model based on the adoption of a data-driven approach to the study of smart service systems that can attempt to address the following research questions:

$R Q 1$ : what are the key enabling factors for the transformation of data into information and potential new value?

$R Q 2$ : what are the main steps for data management that can foster value co-creation within the service journey, between business decision-making process and consumers' buying decisions?

To address the research questions, the work proposes a rereading of the main dimensions of smart service systems according to a data-driven approach to introduce, lastly, a conceptual framework in which the main steps of data management in data-driven smart service systems are identified. The classification of the main dimensions of smart service systems (see paragraph 2) and DDDM (see paragraph 3) derives from a critical re-elaboration of extant studies on Service Science and on information management and business decisions.

\section{Smart Service Systems and the Main Enabling Factors for Value Co-Creation}

In the light of current complexity, extant research on services marketing frames contemporary markets, according to a dynamic and process-based view, as interconnected relationships networks (Chandler \& Vargo, 2011) in which each member is related strictly to the others and contributes actively to the constant reshaping of system's value.

In particular, in Service Science (Spohrer, Maglio, Bailey, \& Gruhl, 2007) such networked organizations are defined as service systems, that are "value co-creation configurations of people, technologies, value propositions, that interact with other service systems internally and externally through shared information" (Spohrer, Vargo, Caswell, \& Maglio, 2008).

The reformulation of markets as service systems complies with the necessity for the investigation of technology-based value co-creation aimed at exploring how the systems connectivity can raise thanks to an harmonized set of technologies, the Internet of Things (Iot, Atzori, Iera, \& Morabito, 2010), that helps managing data flows within and between service systems.

In line with the advent of new technologies, however, the concept of service system has been revised and widened in order to meet the challenges of markets digitization (Lim, Maglio, K. Kim, M. Kim, \& K. Kim, 2016). For this reason, the notion of smart service systems (Barile \& Polese, 2010) has been proposed to define intelligent service systems in which the co-creation of value is based on four key dimensions (Lim \& Maglio, 2019): 1) connection between people and things; 2) communication; 3) data collection; 4) computation.

The transition from service systems to smart service systems can be understood as the outcome of the acknowledged need to adopt a data-based approach to the study of value co-creation emergence. Hence, the reinterpretation of service systems through the lens of smartness can contribute to highlight the implications of ICTs on the interactions people-organizations, on their information sharing and on the entire technological architecture, which enables and intensifies exchanges and creates new relational modalities.

The dynamic and unrepeatable combination of these elements can give birth to value co-creation and to the 
systematic creation of innovation (Carrubbo, Bruni, Cavacece, \& Moretta Tartaglione, 2015; Barile, Ciasullo, Troisi, \& Sarno, 2017) by spreading in the system a constant condition of evolution and innovative tension to re-configuration and proactive co-evolution. The exchanged information- deriving from a continuous collection of "raw" data - is interpreted and targeted to continuous learning, to the implementation of more effective decisions and service improvement $(\mathrm{Ng}, 2015)$.

It follows that the main elements of the service systems (people, organizations, technology, shared information) can be redefined actively by smart technologies which enhance automation and connectivity interactions and empower information exchanges between people and organizations (Lim et al., 2016). As depicted in Figure 1, the interactions organizations-people are strengthened by the intensification of the points of contact or technological channels ("smart" dimension 1: connection). Secondly, the information exchanged are shared in an immediate and transparent way ("smart" dimension 2: communication) by means of technologies that are focused mostly on data collection and analysis ("smart" dimension 3: data collection) through the application of analytics ("smart" dimension 4: computation).

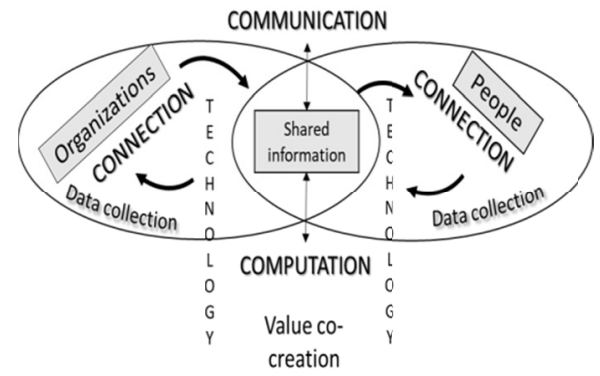

Figure 1. From service systems to smart service systems

The "smart" redefinition of service systems permits to reframe the "old" dimensions of analysis in order to contextualize the use of tools and analytics within intelligent systems that are able to adapt in a changing environment, by improving existing services, by enriching their offering and/or boosting the relationships with consumers (Spohrer \& Demirkan, 2015).

Therefore, the investigation of smart services systems cannot be grounded only on the identification of the systems elements that enable value co-creation (the "what" dimension), but should be aimed at understanding the way in which (the "how" dimension) such elements may be managed, thanks to technology incorporation into interactions and services, through incessant processes of self-adaptation and reconfiguration.

\section{Data-Driven Decision-Making}

The recognized need to re-read value co-creation through the application of new technologies requires the adoption of a value orientation underlying business processes, based on a data mind-set and on strategies aimed at improving decision-making.

In this regard, in extant studies on information and knowledge management, the conceptualization of an approach that leads managers to base their decisions on analytical and critical thinking, the so-called data-driven decision-making (DDDM, LaValle et al., 2011; McAfee \& Brynjolfsson, 2012), has been advanced. The aim is to ensure that the growing amount of data collected is translated into innovative actions that can improve business processes and lead to development and continuous learning.

Data-driven approach, thus, allows at combining constantly research and data collection activities with their proper interpretation leading to the transformation into information and, through incremental processes of exchange, to the renewal of the knowledge acquired (Troisi, Grimaldi, \& Monda, 2019).

Based on a critical re-elaboration of the contributions proposed in the literature (Troisi, Maione, Grimaldi, \& Loia, 2019), it is possible to identify the key dimensions of data-driven approach: 1) learning orientation and consequent diffusion of a data- driven culture; 2) integrated infrastructure of smart technologies; 3) skills; 4) process management; 5) continuous improvement (Spohrer \& Demirkan, 2015).

The first dimension (data-driven culture) is linked to the strategic need to establish- and, then, spread inside and outside the organization- an orientation in which data represents a key strategic lever for the enhancement of choices and decisions at each organizational level (LaValle et al., 2011). By embracing data-driven culture, the 
ability to undertake efficient decisions can be improved thanks to the extraction of insights from data and to the continuous and dynamic adaptation to environmental changes (Medina-Borja, 2015).

From a technological standpoint (Järvinen \& Karjaluoto, 2015), then, it is necessary to implement a proper architecture (integrated infrastructure) that allows at gathering, extrapolating and managing information by increasing data accessibility and reducing complexity (Patron \& Chaffey, 2012).

Next, to extract relevant information from data, human intervention is needed through the application of technical and managerial skills (J. Chen et al., 2013; Gupta \& George, 2016) that can transform data into (oriented) information, (finalized) knowledge and new value. Users and providers should be able to derive utility from data according to their own objectives. If, on the one hand, the main organizational purpose is to align decisions with strategies, users aim at gaining benefits from the purchase of services, by increasing their knowledge and experience and aligning their needs with system's goal.

Thanks to an effective integration and use of information, the value can arise if, thanks to multiple service encounters, data is "used", reconfigured and directed towards common purposes. This complex process, however, requires a careful management of information (process management) between heterogeneous data sources (' $\mathrm{O}$ Neal, 2012) which are, then, processed and optimized within the different organizational contexts of the various systems between the multiple touch points in a recursive logic.

Finally, the circularity of the data-driven process shows that, to manage the insight extracted, technical and management skills and people creativity (Baccarani, 2011) can lead to undertake more effective decisions (related to purchase and re-purchase, for users, and to management or marketing strategies, for the organization). This effectiveness can improve consistently over time by pursuing sustainable competitive advantage, co-evolution and continuous improvement.

Therefore, thanks to the integrated and process- based view proposed herein, the main elements of smart service systems can be reframed based on the key dimensions of data-driven approach, as Figure 2 shows, by means of the following propositions:

1) The adoption of a data-driven culture devoted to continuous learning and to the constant enrichment of knowledge, starting from the data collected, selected and interpreted, implies the re-focusing of organization's strategic objectives towards the internalization of a learning orientation;

2) the connection between people and organizations is enhanced through an integrated infrastructure composed of smart technologies (the central part of Figure 2) that includes sensors, cloud computing systems, mobile applications, software, platforms, etc.;

3) the increased connectivity enriches users-providers encounters thanks to the multiplication of the possibilities of interaction and communication, by improving data integration from different sources and different systems. Data incorporation, that allows resources combination, can result in increased skills of the people involved in the process, by enabling continuous collection of data (such as user's opinions, data on purchasing transactions, etc.) and by transforming the (raw) data into (oriented and relevant) information;

4) the computation of information, carried out by means of an integrated set of analytics, is supervised by decision-makers through process management and optimization that facilitate the transformation of information into knowledge and encourage the emergence of data-based value co-creation;

5) the value, generated from the synergistic knowledge exchanges, is stored within the organization, and "accumulated" as new value and knowledge useful for the stimulation of continuous improvement. 


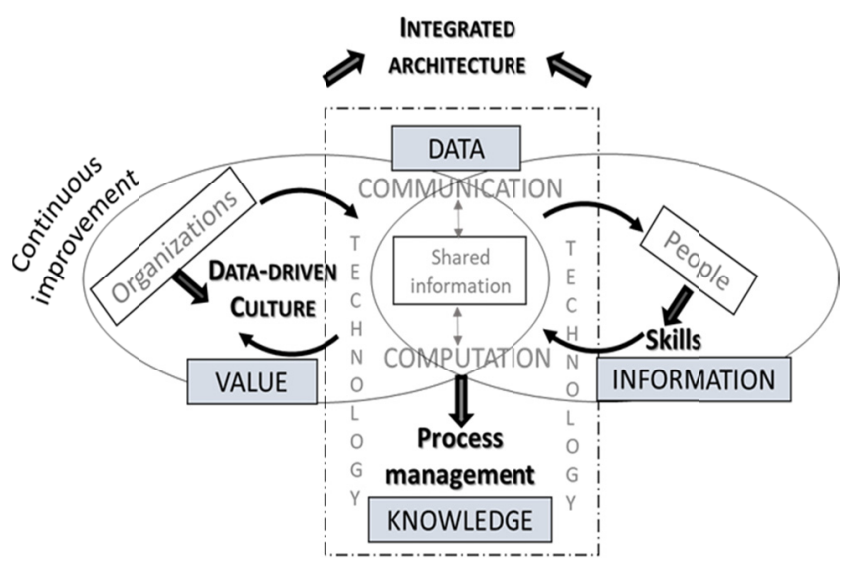

Figure 2. The incorporation of the main steps of data-driven approach into smart service systems

\section{Reinterpreting Customer Journey in Multi-Channel Services}

As Figure 1 and 2 show, in data-based value co-creation processes, it is possible to identify a "space" of co-creation for the consumer and a "space" of co-creation for the provider (see the left side and the right side of the Figures). These two "sections" are separated in the phase in which users and provider do not exchange resources mutually and are integrated during the service encounters (Payne, Storbacka, Frow, \& Knox, 2009).

Therefore, it can be hypothesized that the entire and integrated experience "space" of users and providers, according to a systems view, can redefine the global exchanges of value as a "journey". This all-encompassing vision allows the re-reading of the interactions between actors as a total experience, which starts, firstly, from the expectations and interactions in the pre-delivery, to include, then, the joint exchanges of value linked to the delivery of core services and post- delivery. In this way, users' and providers' experiences can be re-conceptualized as dynamic processes that, passing through the encounter between multiple systems of actors (users-providers, providers-providers or users-users), goes beyond the experience itself, to produce overarching experiences that orient the following exchanges.

In the most recent literature on marketing, the concept of customer journey has been proposed (Patrício, Fisk, Falcão e Cunha, \& Constantine, 2011; Zomerdijk \& Voss, 2010) to define the increased possibilities of interactions between providers and consumers through the dissemination of numerous points of contact (Voorhees et al., 2017: Lemon \& Verhoef, 2016).

It can be noticed that this concept seems to comply with the data-based value co-creation process in smart service systems described above. By applying customer journey to the broadened view that integrates DDDM and smart service systems, customer journey can be widened to include and encompass service encounters and experiences, by overcoming any distinction between the roles of users and providers, to reach a global service journey. The recursion of decision-making process (described in paragraph 2) highlights the commonalities between DDDM and the concept of the journey that can be redefined as a global notion that involves consumer's decision, concerning consumption choices, and organization's decisions, aimed at facilitating, monitoring and improving service provision.

By reinterpreting and extending customer journey beyond the space of co-creation of consumers, it is possible to conceive a service journey that overcomes any distinction between suppliers and consumers, by redefining the mechanisms of data-driven co-creation as a "journey" that occurs across multiple points of contact. According to this conceptualization, as depicted in Figure 3, the service encounter refers to the interactions in-use (Payne, Storbakca, \& Frow, 2008), while actor's interpretation of these interactions shapes the experiences, that, in turn, give life to the journey, as a set of embedded and recursive interactions and experiences which increase the final value of the system. In line with service-dominant logic (Breidbach \& Maglio, 2016), there is no difference between the roles of users and providers, and their related value exchanges, and between $\mathrm{B} 2 \mathrm{~B}, \mathrm{~B} 2 \mathrm{C}$ or $\mathrm{C} 2 \mathrm{C}$ marketing relations (Polese, Sarno, Troisi, \& Grimaldi, 2018). Hence, the systems re-reading herein advanced introduces a transcendent vision that makes the service system itself as a unit of analysis- rather than the different actors included in it-, by proposing an abstraction of value co-creation. 


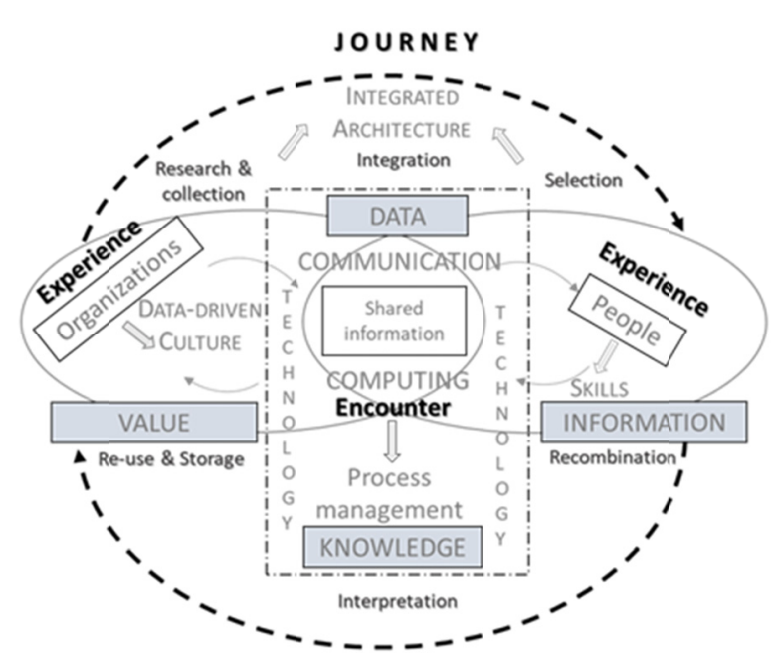

Figure 3. From service encounter to service experience and service journey

For instance, one can think of the possibilities offered from new technologies, in which providers can examine and intercept consumer behaviour by detecting users' evaluations on service reliability and performance. In this way, the traditional asymmetry of information in the relationship users-providers is erased and suppliers can be provided with the possibility to choose the most eligible customers to be able to use the service (e.g. hosts on Airbnb that can decide to accept given customers). Decision-making processes of supply (provider), on the one hand, and of purchase (user), on the other hand, can coincide by attaining the joint creation of value.

The numerous touchpoints in multi-channel services can amplify the concept of journey, by allowing the identification of different and interconnected "areas of value co-creation" of users and providers that involve value expectations, value perceptions and effective value co-creation (in the middle of the Figure 3). Therefore, service exchanges in data-based smart service systems can be read as the result of complex transformations of value over four different spheres:

1) Organization: organizational dimension (experience);

2) People: human sphere involving users and employees at each level (experience);

3) Service encounter: interactions, resource integration and joint creation and co-creation of value (intersecting area people-organization);

4) Service journey: circular and global process (all-encompassing organizations and people experiences and their intersection) that consists of data collection, information sharing, recombination of knowledge and creation of value, which embraces the entire service experience.

\section{A Conceptual Model for Data-Driven Smart Service Systems}

Starting from the application of data-driven orientation to service systems, in line with the steps of Big Data lifecycle (Lemon \& Verhoef, 2016), which defines the procedural stages for data utilization, it is possible to reinterpret the diverse phases of the service journey as complex processes of data research, integration, collection, selection, analysis, interpretation, storage and reuse. Thus, data management in smart service systems can be conceptualized through a circular model (see Figures 4) in which the new knowledge and value acquired at the end of the cycle are used to monitor, improve and innovate constantly the service, the quality of the interactions and the co-created value.

Therefore, as a result of the matching between the enabling factors of value co-creation in smart service systems (RQ1, see par. 2) and the strategic dimensions of DDM (see par. 3), the stages of collection, selection and management of data that foster the transition from data to information to knowledge and value can be identified (RQ2). The steps for a data-based approach to value co-creation are:

1) data-driven orientation and identification of a strategic plan and objectives for the management of data exchange (data research and collection);

2) integration of resources and information sharing through timely and transparent communication (sharing and integration); 
3) interiorization of the information exchanged to enhance actor's skills (selection to focus on relevant information);

4) recombination of information and transformation into data;

5) extraction of knowledge from information (interpretation);

6) re-sharing of the knowledge acquired and co- creation of new value (reuse and storage for continuous improvement).

Each step will be described below with reference to both organization's (provider, supplier and other systems) and people's sphere (abstraction at the individual level of attitude, skills and other resources). The three sections, (1. people experience; 2. organization experience; 3 . encounter), strictly interconnected, are separated herein graphically and conceptually to meet theoretical aims (see Figure 4). For each phase, it will be defined: 1) the different touchpoints based on new technologies; 2) the entered resources; 3) objectives.

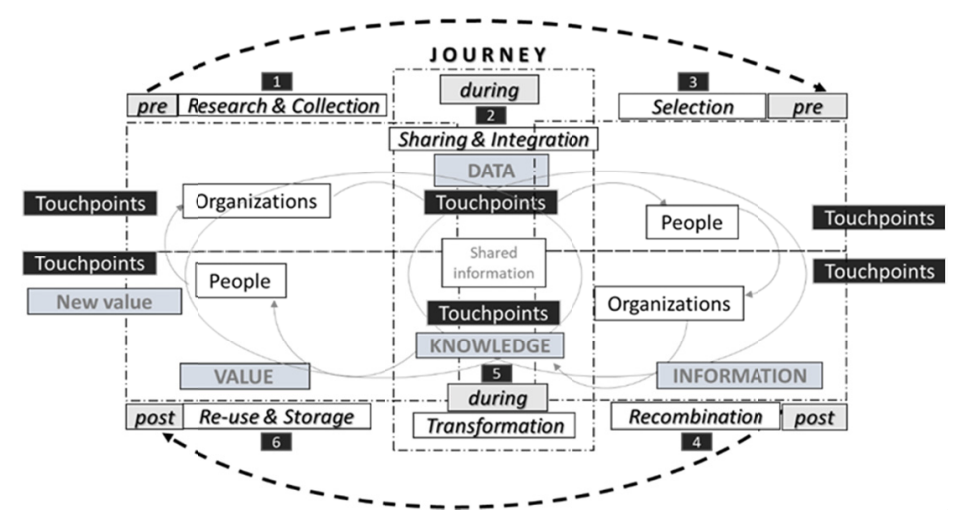

Figure 4. The main steps for data management in service journey

In the first phase (data research \& collection, Figure 5), thanks to a data-driven orientation, organizations perform the preliminary identification of needs, concerning user's sphere, and of the strategic objectives, concerning organizations' sphere. Moreover, organizations seek to foresee value expectations of the actors involved by proposing. Based on this analysis, focused on a learning orientation, it is possible to shape user-provider, provider-provider or user-user interactions and experiences according to the needs and the objectives identified through data research.

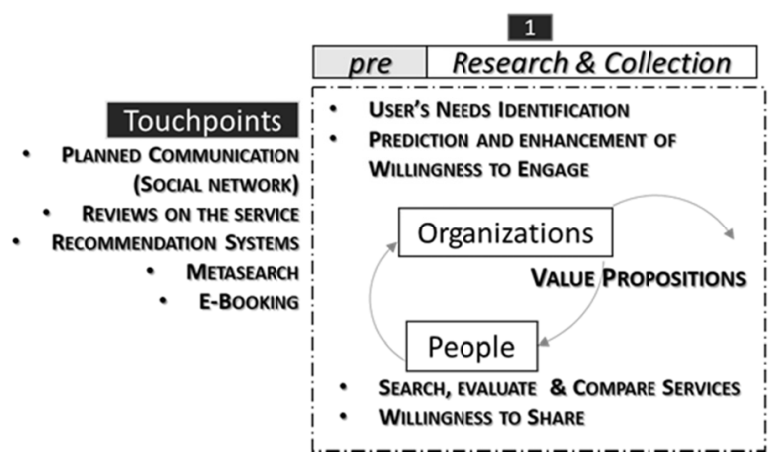

Figure 5. Research \& collection: touchpoints, resources exchanged, objectives

From an organizational point of view, various touchpoints are settled to facilitate the data-information-knowledge flows, which must be managed to be transform data into value.

Providers aim not only at intercepting users' needs from external sources or informal and unsolicited communications (e.g. review of evaluation websites of the services), but also at supporting purchase motivations through voluntary attractive communications with strong emotional impact (through social networks, for example). Since the goal is to spread organizational culture, companies need to establish and share their value 
propositions to involve users and stimulate their desire to be involved (willingness to engage users on the part of providers is complementary to willingness to share on the part of users).

Social networks and online communities are the technological tools used to involve users in the proposition of value, and to ensure that the emergence of their needs matches with the search for new strategic goals on the part of companies. These platforms have emotional and informational purposes that can increase brand awareness and users' willingness to purchase. In particular, users can be involved in the design phase (pre-delivery) in projects for the launch of new products or in research on customers based on focus groups or critical incident, aimed at understanding the expectations on services.

At the same time, users search for information on services via web sites, news aggregators, review sites and portals, search engines and metasearch, to gather and compare existing opinions on services (e.g. the online travel agencies, OTA, in the tourism sector). The ICTs tools that support metasearch play a dual role: on one hand, users employ them as channels to compare prices, conditions and availability of service; on the other hand, companies adopt these platforms to display data on consumers about the buying process and about the research path (organic search, tracking systems and GPS).

In addition to information on the quality of services, users can also find instructions and guidelines on the service, receive suggestions about purchase (through recommendation systems and location-based services) or make online reservations.

The objectives of the touchpoints, in this phase, are: 1) for consumers, the understanding, of the values proposed by organizations; 2) for organizations, users' motivations and needs. Social media and analytics (sentiment analysis or web crawler for research preferences) are key tools for insights collection.

In the second phase (information sharing \& integration and communication, Figure 6), the various actors involved exchange data, by modifying them and turning into information aimed towards the achievement of the objectives formulated in the first phase. In this way, through the encounter, knowledge, sentiment and consumer experiences encounter the orientation, values and culture of the providers.

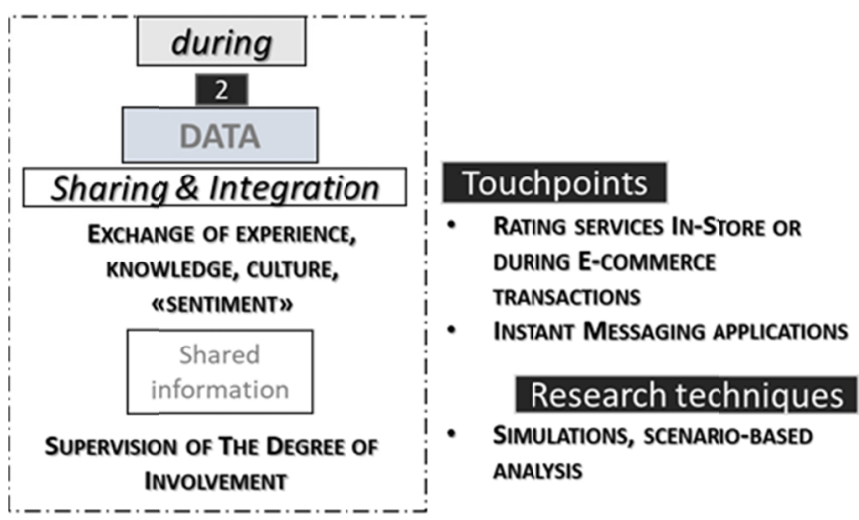

Figure 6. Information integration and sharing: touchpoints, resources exchanged, objectives

Actors (organization-people) gather the degree of involvement of each other in progress, by monitoring any changes in the attitude. For instance, one can think of the rating tools proposed during the delivery of services (in store, via tablet or computers with touch screens, or during e-commerce transactions). There are also a series of software programs to manage and track purchases, which provide users with location-based information to understand the "movements" of users in e-commerce sites, or physical point of sales (simulation and scenario-based analysis to rebuild purchasing processes). Moreover, in some service sectors (such as tourism and hospitality) instant messaging applications such as WhatsApp can be used from hosts to keep in contact with travellers all day. The main objectives pursued by the implementation of the touchpoints in this phase are the experience modulation through face-to-face interactions and the active redefinition of information that will be converted into value.

In the third phase (selection), consumers and businesses select the information shared mutually in order to make them useful and relevant to skim the data exchanged. Thanks to the extraction of meaning from the collected information, each systems member can participate in knowledge co-creation. In this phase, actor's experiences 
are reshaped after the alignment with system's goal and thanks to the acceptance of providers' value proposition. A key role is played by the skills of organizational members with technical and methodological skills able to extract value from data, by directing the information and knowledge gained toward the improvement of services.

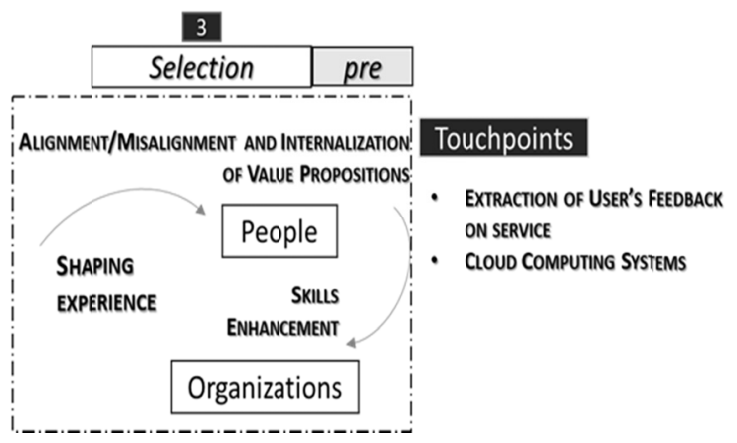

Figure 7. Information selection: touchpoints, resources exchanged, objectives

The objectives of the touchpoint used in this phase include the consolidation of the information received and the increase of user involvement in the proposition of new products or service improvement. Technology permits to keep users and organizations in constant contact, even after the service delivery. In e-commerce, for instance, there are ad hoc systems to manage the process of purchase and the status of orders to gather user's feedback at any time by proposing "recall" communication (e.g. banners to remember selected products that have never been purchased or to promote products similar to the ones purchased).

In addition, a series of analytics, such as cloud computing systems, allow companies to store information about the orders, the level of productivity or the inventory disposal.

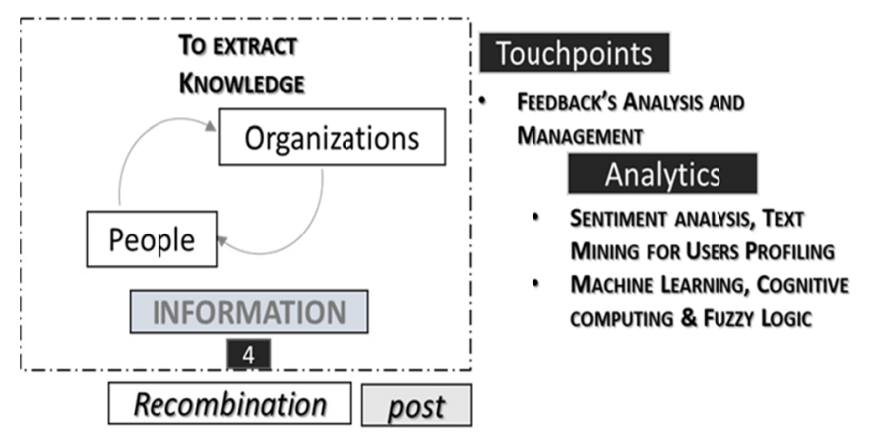

Figure 8. Information recombination: touchpoints, resources exchanged, objectives

Thanks to the recombination of the information exchanged, organizations and users can co-create knowledge (transformation, see Figure 9) and develop new ideas by creating a common background (co-creation) for the joint planning of new services. The feedback extracted in the previous phase can be analysed by means of text mining and sentiment analysis to profile users and machine learning systems to understand the weaknesses of service or predict future behaviours.

Machine learning techniques are predictive analytics, which require statistical learning and network science, to translate data resources into actionable knowledge (Sundaran, Ganapathy, \& Sudhakara, 2017). Cognitive computing systems are based on machine learning and are devoted to enable decision-making thanks to circular learning mechanisms. These techniques can support human decisions and guide problem solving by detecting alternative courses of action starting from data. Based on learning cycle principles, cognitive computing solutions (Y. Chen, Argentinis, \& Weber, 2016; Hurwitz et al., 2015) start from the elaboration of a fixed vocabulary to deduce and learn the meaning of new words based on contextual clues. Moreover, fuzzy logic and decision-support systems can be employed to evaluate the weights of participants in decision-making paradigm to support more effectively the undertaking and the implementation of decisions.

In this step, organizations should employ a process management to guide and direct the ongoing co-creation of 
value, which will arise in the last phase, by interacting with users through a variety of touchpoints that aim at increasing their active engagement in the proposed new value. For instance, open platforms (such as crowdsourcing platforms or ad hoc platform that involve users in the launch of new services) or Living lab can foster the joint proposal of new services.

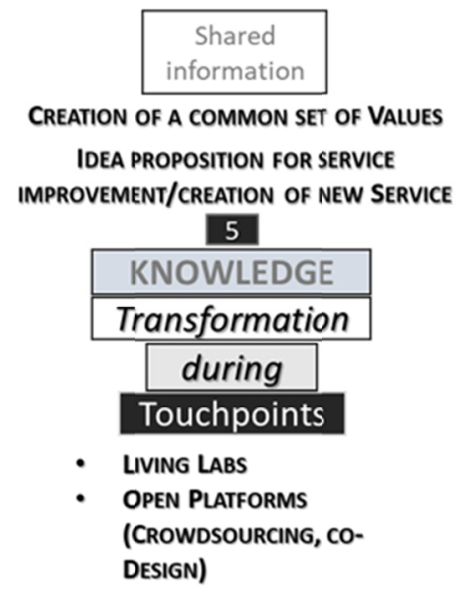

Figure 9. Transformation of information into knowledge: touchpoints, resources exchanged, objectives

Finally, in the phase of reuse (Figure 10), after having "captured" value from data integration and from the enhancement of knowledge between the different systems and different business functions, organizations can share the results of data analysis. Moreover, the continuous dissemination and reallocation of the new value produced can improve the ability to develop learning cyclically and to develop, then, potential innovation (Baccarani \& Golinelli, 2014). Eventually, the system is enriched through a cognitive synergy greater than the sum of individual contributions made by each member.

After the evaluation of the effectiveness of the value exchange and of the goodness of the decisions undertaken thanks to insights extracted, the process can restart. In this way an infinite cycle of data collection, organization and synthesis supporting decision-making (Ikemoto \& Marsh, 2007; Aagesen \& Krogstie, 2011) can be established. In this process, users should not only buy products and services but also get in touch with providers and choose whether to become loyal consumers. Providers, instead, can increase competitiveness and organizations' know-how to pursue sustainable competitive advantage.

The phase of re-use can be enhanced through the adoption of cloud systems to store data and create a global data system along supply chain, between the various touchpoints in a multi-channel perspective. The recommendation systems and the various online tracking systems, as well as reviews written by users (voluntarily or involuntarily), allow the collection of experiences to guide and predict future behaviours, through the construction of databases and data warehouses and a set of tools to manage service after-sales (returns, complaints, refunds, etc.).

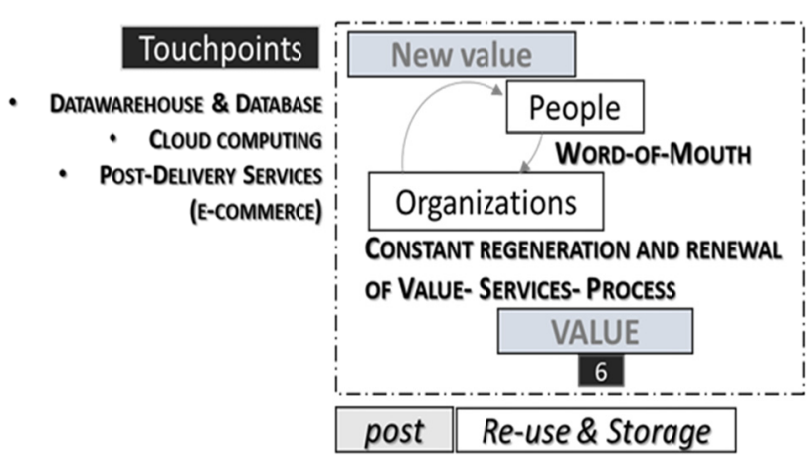

Figure 10. Re-use and data storage for continuous improvement: touchpoints, resources exchanged, objectives 
Therefore, the objective of the use of technology strategy is the translation experience emotional attachment to the brand (emotional attachment) to retain the user during the journey and in its continuation. In this sense, social networks help to "engage" users in everyday life beyond the service delivery times, establishing and maintaining personal relationships with them over time. Stretch the journey involves encourage users to express their opinions and forms of "affection" towards the brand after the purchase, by the provider, and provides for the incorporation of the service in its socio-cultural context of reference, by users that generate word of mouth (Baccarani, Ugolini, \& Bonfanti, 2015).

As Figure 11 shows, the steps described above are managed through an adequate infrastructure composed of a set of technological tools implemented before, during and after service delivery.

These tools can be classified into: 1) social networks, websites, portals, banners for unidirectional advertising; 2) social networks, portals, booking sites for the exchange comments between users and between users and providers; 3) mobile applications and instant messaging applications for real-time communication; 4) data and research analytics to extract data by using cloud systems, machine learning, text mining, sensors, web scraping and API. The diversification of the technological instruments in the various stages, aimed at pursuing various goals and objectives, ensures the efficiency of multi-channel strategies (Neslin et al., 2006; Lemon \& Verhoef, 2016) and of successfully value orchestration and regeneration.

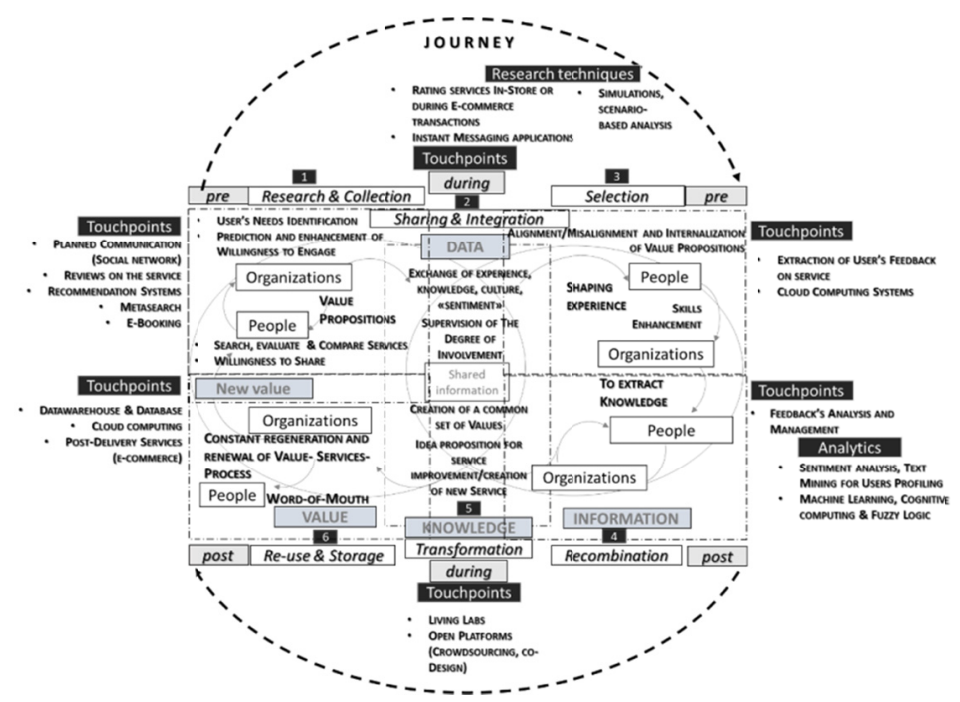

Figure 11. Data management, information transformation and co-creation of knowledge and value in service journey

\section{Conclusions and Implications}

The proposition of a conceptual model that reframes smart service systems according to a data-driven approach to decision-making permits to redefine technology-enabled value exchanges as service journeys. In this complex process, users and providers decision-making is supported by the transformation and reshaping of value through multiple touchpoints.

This integrated approach allows at addressing the research questions introduced in the first part of the work:

RQ1- The main enabling factors that allow at transforming the collected data into value are fostered by:

1) the adoption of an all-encompassing approach to data management; 2) the implementation of an integrated architecture consisting of multiple touchpoints available to users and providers; 3) the constant integration of resources activated by the actors, managed in a process-based vision; 4) the co-creation of new skills, increased experience and knowledge and the constant generation and regeneration of co-created value.

RQ2- Multi-channel service strategies facilitate the transition from service encounter to experience, to service journey that allows co-creating value between organizational decisions processes and consumer buying processes through the following steps:

1) identification of strategic plan and objectives (data collection and research); 2) integration through timely and transparent communication resources and sharing information (information integration and sharing); 3) information selection; 4) recombination (data transformation into information); 5) extraction of knowledge from 
relevant information (data interpretation); 6) co-creation of new value (data storage for continuous improvement).

The adoption of a systems and process-based view can allow at espousing a synthesis perspective that mediates between: 1) the exploration of the enabling elements for value co-creation (RQ1, technologies, information exchange, skills, process management); 2) the way in which these elements can be harmonized to create new value (rq2, data management stages, transformation of data into information and value).

Therefore, from a theoretical point of view, the work contributes to shed light on the transformative role of technology (Akaka et al., 2019), by advancing the first steps to address a gap deriving from extant research on Service Science. In fact, a focus on the analysis of the technological drivers for value co-creation can be revealed that implies a lack of studies that do not investigate adequately how new value can be co-created in complex service systems (Breidbach and Maglio, 2016). The proposition of a synthesis view permits to conceptualize not only the enabling elements for value co-creation but also the modalities for the dynamic combination of these elements to turn data-information-knowledge into value and renew value for continuous improvement.

Moreover, the suggestion of a model that describes the different phases for data analysis (and the multiple touchpoints that organizations can introduce to differentiate omnichannel strategies at each phase) can reveal new data-driven methods to drive customer satisfaction and deliver actionable insights (Lemon and Verhoef, 2016).

From a managerial point of view, the introduction of a classification with the different phases of data-driven decision-making can help managers understanding how to redefine their strategies and business tactics, business models and marketing decisions and management thanks to the most appropriate strategies for data management.

By categorizing the multiplicity of technological instruments, resources and data management phases for value co-creation, the study can stimulate decision-makers to redefine service exchanges as journeys to take advantage from the insights collected at each stage of the process. The ability to manage and integrate the use of multiple technological channels with the pursuit of the main marketing objectives -such as the increase of users' engagement, the improvement of relationships with customers (CRM) or the attainment of loyalty- can contribute to the creation and co-creation of value along the entire supply chain and to the attainment of continuous improvement. Thanks to the integration of different touchpoints, managers can be encouraged to develop differentiated omnichannel strategies for different targets and for different phases of the journey to increase engagement and, then, the creation of new knowledge.

Moreover, the study debates the key role of managerial orientation and attitude to the use of technology and to the dissemination of a common set of values for the efficient employment of ICTs. By emphasizing the need for a proactive and innovation-oriented mind-set, the model proposed can help developing strategies to manage the smart technologies and to exploit the various possibilities offered by the different types of existing tools (to predict users' perception, to detect the "sentiment", to store users' behaviour, to foster loyalty or the improvement of the service). In this way, the strong impact of technology on service improvement and on the production of innovation and sustainable value is highlighted.

The main limitation of the work is related to the conceptual nature of the analysis that re-conceptualizes data-driven approach and service journey based on a critical re-elaboration of literature without conducting an empirical research. The study can be intended as a first conceptual step for future research aimed at performing qualitative observation and/or measurement of data-based value co-creation.

Thus, the application of a case study could corroborate, modify, extend or further specify the conceptual model introduced. The multidimensional nature of the model and the complexity of the concepts analysed require the adoption of a mixed method and the combination of multiple techniques such as semi-structured interviews, focus groups, observation. For this reason, in an exploratory stage, the qualitative approach can be the most suitable methodological framework to understand in depth the processes of decision-making and information management in data-driven organizations.

Future empirical research based on the model herein developed could examine a specific service sector. In particular, the application to B2B marketing could permit to emphasize the importance of customer relations to perform an analysis that goes beyond the differences between users' and providers' roles. In particular, organizations such as consulting firms, which operate between $\mathrm{B} 2 \mathrm{~B}$ and $\mathrm{B} 2 \mathrm{C}$ markets, are devoted to the adoption of multi-channel marketing strategies and could be suitable for the analysis of the impact of data on the redefinition of business strategies and on the relationship between value co-creation and innovation (data-driven innovation). 


\section{References}

Aagesen, G., \& Krogstie, J. (2011). Service delivery in transformational government: model and scenarios. Electronic Governmet, an International Journal, 8(2-3), 242-258. https://doi.org/10.1504/EG.2011.039839

Atzori, L., Iera, A., \& Morabito, G. (2010). The internet of things: A survey. Computer networks, 54(15), 2787-2805. https://doi.org/10.1016/j.comnet.2010.05.010

Baccarani, C. (2011). Il vento del cambiamento. Sinergie, 86, 7-10.

Baccarani, C., \& Golinelli, G. M. (2014), Le parole dell'innovazione, Sinergie, 94(May-Aug), 9-14.

Baccarani, C., Ugolini, M., \& Bonfanti, A. (2015). A conceptual service quality map: The value of a wide opened perspective. In Toulon-Verona Conference" Excellence in Services".

Barile, S., \& Polese, F. (2010), Smart service systems and viable service systems: Applying systems theory to service science. Service Science, 2(1-2), 21-40. https://doi.org/10.1287/serv.2.1_2.21

Barile, S., Ciasullo, M. V., Troisi, O., \& Sarno, D. (2017). The role of technology and institutions in tourism service ecosystems: Findings from a case study. The TQM Journal, 29(6), 811-833. https://doi.org/10.1108/TQM-06-2017-0068

Breidbach, C. F., \& Maglio, P. P. (2016). Technology-enabled value co-creation: An empirical analysis of actors, resources, and practices. Industrial Marketing Management, 56, 73-85. https://doi.org/10.1016/j.indmarman.2016.03.011

Brynjolfsson, E., Hitt, L. M., \& Kim, H. H. (2011). Strength in numbers: How does data-driven decision-making affect firm performance? Available at SSRN 1819486. https://doi.org/10.2139/ssrn.1819486

Cao, L., \& Li, L. (2015). The Impact of Cross-Channel Integration on Retailers' Sales Growth. Journal of Retailing, 91(2), 198-216. https://doi.org/10.1016/j.jretai.2014.12.005

Carrubbo L., Bruni R., Cavacece Y., \& Moretta Tartaglione A. (2015). Service system platforms to improve value co-creation: Insights for translational medicine. System Theory and Service Science: Integrating Three Perspectives in a New Service Agenda. Napoli: Giannini Editore.

Chandler, J. D., \& Vargo, S. L. (2011). Contextualization and value-in-context: How context frames exchange. Marketing theory, 11(1), 35-49. https://doi.org/10.1177/1470593110393713

Chaffey, D., \& Patron, M. (2012). From web analytics to digital marketing optimization: Increasing the commercial value of digital analytics. Journal of Direct, Data and Digital Marketing Practice, 14(1), 30-45. https://doi.org/10.1057/dddmp.2012.20

Chen, J., Chen, Y., Du, X., Li, C., Lu, J., Zhao, S., \& Zhou, X. (2013). Big data challenge: a data management perspective. Frontiers of Computer Science, 7(2), 157-164. https://doi.org/10.1007/s11704-013-3903-7

Chen, Y., Argentinis, J. E., \& Weber, G. (2016). IBM Watson: how cognitive computing can be applied to big data challenges in life sciences research. Clinical therapeutics, 38(4), 688-701. https://doi.org/10.1016/j.clinthera.2015.12.001

Cooper, H. M. (1988). Organizing knowledge syntheses: A taxonomy of literature reviews. Knowledge in society, l(1), 104. https://doi.org/10.1007/BF03177550

Dulock, H. L., \& Holzemer, W. L. (1991). Substruction: Improving the linkage from theory to method, Nursing Science Quarterly, 4(2), 83-87. https://doi.org/10.1177/089431849100400209

Erevelles, S., Fukawa, N., \& Swayne, L. (2016). Big Data consumer analytics and the transformation of marketing. Journal of Business Research, 69(2), 897-904. https://doi.org/10.1016/j.jbusres.2015.07.001

Gandomi, A., \& Haider, M. (2015). Beyond the hype: Big data concepts, methods, and analytics. International Journal of Information Management, 35(2), 137-144. https://doi.org/10.1016/j.ijinfomgt.2014.10.007

Gupta, M., \& George, J. F. (2016). Toward the development of a big data analytics capability. Information \& Management, 53(8), 1049-1064. https://doi.org/10.1016/j.im.2016.07.004

Hurwitz, J., Kaufman, M., Bowles, A., Nugent, A., Kobielus, J. G., \& Kowolenko, M. D. (2015). Cognitive computing and big data analytics (p. 28). Hoboken: John Wiley \& Sons.

Ikemoto, G. S., \& Marsh, J. A. (2007). Cutting Through the "Data-Driven" Mantra: Different Conceptions of Data-Driven Decision Making. Yearbook of the National Society for the Study of Education, 106(1), 105-131. https://doi.org/10.1111/j.1744-7984.2007.00099.x 
Kagermann, H., Lukas, W. D., \& Wahlster, W. (2011). Industrie 4.0: Mit dem Internet der Dinge auf dem Weg zur 4. industriellen Revolution. VDI nachrichten, 13(1). Available at: http://www.wolfgang-wahlster.de/wordpress/wp-content/uploads/Industrie_4_0_Mit_dem_Internet_der_Din ge_auf_dem_Weg_zur_vierten_industriellen_Revolution_2.pdf

LaValle, S., Lesser, E., Shockley, R., Hopkins, M. S., \& Kruschwitz, N. (2011). Big data, analytics and the path from insights to value. MIT Sloan Management Review, 52(2), 21. Retrieved from http://foresight.ifmo.ru/ict/shared/files/201309/1_9.pdf

Lemon, K. N., \& Verhoef, P. C. (2016). Understanding customer experience throughout the customer journey. Journal of marketing, 80(6), 69-96. https://doi.org/10.1509/jm.15.0420

Lim C., Maglio P. P., Kim, K., Kim, M., \& Kim, K. (2016). Toward Smarter Service Systems through Service-oriented Data Analytics. Proceedings of 2016 I.E. International Conference on Industrial Informatics, 1-6. https://doi.org/10.1109/INDIN.2016.7819295

Lim, C., \& Maglio, P. P. (2019). Clarifying the Concept of Smart Service System. In Handbook of Service Science, Volume II (pp. 349-376). Springer, Cham. https://doi.org/10.1007/978-3-319-98512-1_16

McAfee, A., \& Brynjolfsson, E. (2012). Big data: the management revolution. Harvard Business Review, 90, 60-66. Retrieved from http://hbr.org/2012/10/big-data-the-management-revolution/ar

Medina-Borja, A. (2015). Editorial column-smart things as service providers: a call for convergence of disciplines to build a research agenda for the service systems of the future. Service Science, 7(1) https://doi.org/10.1287/serv.2014.0090

Mele, C., \& Polese, F. (2011). Key dimensions of service systems in value-creating networks. In H. Demirkan, J. Spohrer, \& V. Krishna (Eds.), The Science of Service Systems. Service Science: Research and Innovations in the Service Economy (pp. 37-59). Boston, MA: Springer. https://doi.org/10.1007/978-1-4419-8270-4_3

Neslin, S., Grewal, D., Leghorn, R., Shankar, V., Teerling, M., Thomas, J., \& Verhoef, P. (2006). Challenges and opportunities in multichannel customer management. Journal of Service Research, 9(2), 95-112. https://doi.org/10.1177/1094670506293559

Ng, I. (2015). The Internet of Everything and the Future of Service. Speech, 2015 Frontiers in Service Conference in San Jose, CA. Retrieved from http://hubofallthings.com/hat-in-the-usa/

O’Neal, C. (2012). Data-Driven Decision Making. Washington, D.C.: International Society for Technology in Education.

Ortiz-Repiso, V., Greenberg, J., \& Calzada-Prado, J. (2018). A cross-institutional analysis of data-related curricula in information science programmes: A focused look at the iSchools. Journal of Information Science, https://doi.org/10.1177/0165551517748149

Patrício, L., Fisk, R. P., Falcão e Cunha, J., \& Constantine, L. (2011). Multilevel service design: from customer value constellation to service experience blueprinting. Journal of service Research, 14(2), 180-200. https://doi.org/10.1177/1094670511401901

Payne, A. F., Storbacka, K., \& Frow, P. (2008). Managing the co-creation of value. Journal of the academy of marketing science, 36(1), 83-96. https://doi.org/10.1007/s11747-007-0070-0

Payne, A., Storbacka, K., Frow, P., \& Knox, S. (2009). Co-creating brands: Diagnosing and designing the relationship experience. Journal of Business Research, 62(3), 379-389. https://doi.org/10.1016/j.jbusres.2008.05.013

Polese, F., Barile, S., Caputo, F., Carrubbo, L., \& Waletzky, L. (2018). Determinants for Value Cocreation and Collaborative Paths in Complex Service Systems: A Focus on (Smart) Cities. Service Science, 10(4), 397-407. https://doi.org/10.1287/serv.2018.0218

Polese, F., Sarno, D., Troisi, O., \& Grimaldi, M. (2018), From B2B to A4A: An Integrated Framework for Viable Value Co-Creation. Mercati \& competitività, 3, 135-161. https://doi.org/10.3280/MC2018-003008

Rangaswamy, A., \& Van Bruggen G. (2005). Opportunities and Challenges in Multichannel Marketing: An Introduction to the Special Issue. Journal of Interactive Marketing, 19(2), 5-11. https://doi.org/10.1002/dir.20037

Spohrer, J. C., \& Demirkan, H. (2015). Introduction to the smart service systems: Analytics, cognition, and innovation minitrack. In 2015 48th Hawaii International Conference on System Sciences (pp. 1442-1442). 
IEEE. https://doi.org/10.1109/HICSS.2015.175

Spohrer, J., Maglio, P. P., Bailey, J., \& Gruhl, D. (2007). Steps toward a science of service systems. Computer, 40(1), 71-77. https://doi.org/10.1109/MC.2007.33

Spohrer, J., Vargo, S. L., Caswell, N., \& Maglio, P. P. (2008). The service system is the basic abstraction of service science. In Hawaii International Conference on System Sciences, Proceedings of the 41st Annual, 104-104. https://doi.org/10.1109/HICSS.2008.451

Sundaran, K., Ganapathy, V., \& Sudhakara, P. (2017, February). Fuzzy logic based unequal clustering in wireless sensor network for minimizing energy consumption. In 2017 2nd International Conference on Computing and Communications Technologies (ICCCT) (pp. 304-309). IEEE. https://doi.org/10.1109/ICCCT2.2017.7972283

Troisi, O., Grimaldi, M., \& Monda, A. (2019). Managing Smart Service Ecosystems Through Technology: How ICTs Enable Value Cocreation. Tourism Analysis, 24(3), 377-393. https://doi.org/10.3727/108354219X15511865533103

Troisi, O., Maione, G., Grimaldi, M., \& Loia, F. (2019). Growth hacking: Insights on data-driven decision-making from three firms. Industrial Marketing Management. https://doi.org/10.1016/j.indmarman.2019.08.005

Voorhees, C. M., Fombelle, P. W., Gregoire, Y., Bone, S., Gustafsson, A., Sousa, R., \& Walkowiak, T. (2017). Service encounters, experiences and the customer journey: Defining the field and a call to expand our lens. Journal of Business Research, 79, 269-280. https://doi.org/10.1016/j.jbusres.2017.04.014

Zomerdijk, L. G., \& Voss, C. A. (2010). Service design for experience-centric services. Journal of Service Research, 13(1), 67-82. https://doi.org/10.1177/1094670509351960

\section{Copyrights}

Copyright for this article is retained by the author(s), with first publication rights granted to the journal.

This is an open-access article distributed under the terms and conditions of the Creative Commons Attribution license (http://creativecommons.org/licenses/by/4.0/). 